\title{
Assessment of Factors Associated With Practice and Knowledge of Essential Newborn Care Among Nurse and Midwives in Assosa Zone Governmental Health Facilities, Western Ethiopia, 2021.
}

\section{Diriba Bayisa}

Assosa University

Berhane Teklay

Assosa University

Mabratu Demissie

Assosa University

Hunduma Dina ( $\square$ hunde4mother@gmail.com )

Assosa University

\section{Research Article}

Keywords: Essential newborn care, knowledge, practice, Nurse and midwives, Ethiopia

Posted Date: January 31st, 2022

DOI: https://doi.org/10.21203/rs.3.rs-1210942/v1

License: (c) (1) This work is licensed under a Creative Commons Attribution 4.0 International License.

Read Full License 


\section{Abstract}

Introduction: Promoting basic newborn care skills and practices is a cost-effective approach to improving newborn health outcomes. Therefore, this study aimed to assess the essence of the essential knowledge about newborn care, practices and related factors among nurse and midwives in western Ethiopia.

Objective: This study intended to assess factors associated with Practice and knowledge of Essential newborn care among nurse and midwives working in Assosa Zone governmental health facility, western Ethiopia, 2021.

Methods: Institutional based cross-sectional study design was conducted among nurses and Midwives those engaged in newborn care services in selected public health facilities in Assosa Zone western Ethiopia. A Convenient sampling technique was applied. Data was collected by interviewer administered structured questionnaires.

Data processing and analysis: The collected data was entered into Epi data 3.1version and analyzed by using SPSS version 26. The strength of association between independent and dependent variables was measured by odd ratios with $95 \% \mathrm{Cl}$ at $\mathrm{p}$-value of $<0.05$.

Result: $98 \%$ nurses and midwives w. Mean value of good knowledge and good practice of essential newborn care were $61.7 \%$ [95\% $\mathrm{Cl}(56.4,69.8)]$ and $41.5 \%$ [95\% $\mathrm{Cl}(38.3,48.5)]$ respectively. Being trained, educational qualification, availability of newborn care materials and work experience were significantly associated with knowledge practice of essential newborn care.

Conclusion: This study identified that knowledge of essential newborn care was average among Nurse and Midwifes; however, the practice of essential newborn care was very low compared to other studies in Ethiopia. Therefore factors identified; in service training, improving educational qualification and increasing accessibility of new born care materials at all facility level are interventional areas to bring required knowledge and practice of Essential new born care.

\section{Introduction}

The transition from intrauterine to extra uterine life is dramatic and requires significant and effective physiological changes by the baby to ensure survival [1]. Not only the time of birth, but also the first hour after birth has a major impact on the survival, future health and well-being of a newborn. Health workers play an important role at the time of birth, and care during this time is critical to avoid complications and ensure survival[2]. Only qualified care during labor and delivery with immediate complication management can prevent around $50 \%$ of newborn mortality and $45 \%$ of intra-partum stillbirths [3].

The Essential Newborn Care Protocol is a set of time-bound, chronologically ordered standard procedures that a baby receives at birth to improve the health of newborns through interventions before conception, during pregnancy, during and shortly after birth, and in the postnatal period improve[4]. There are four 
heart of the protocol of ENC ; which are time bound interventions: immediate drying, skin-to-skin contact, followed by disconnecting the umbilical cord after 1 to 3 minutes, not separating the baby from the mother, and starting breastfeeding [5].

Essential newborn care has standardized and effective procedural steps: drying and stimulating, assessing breathing, umbilical cord care, keeping the newborn warm (preventing hypothermia), initiating breastfeeding within the first hour, administering eye drops / eye ointment, administering vitamin $\mathrm{K}$ intramuscularly, newborn identification straps, weighing the newborn, when stable and warm, record all observations and treatments, postpone bathing the baby for 24 hours after birth[6]. Combined with adequate knowledge and practice of neonatal care in all healthcare facilities in the postnatal period, $75 \%$ of neonatal mortality, as well as thousands of stillbirths and maternal mortality, can be prevented. Therefore, WHO recommends basic neonatal care measures that should be given to all newborns at birth to protect against neonatal morbidity and mortality [7].

Every day Globally; Nearly 7,000 newborns die, accounting for nearly half of all deaths in children under five; But the mild neonatal death rate (NMR) was halved from 36.6 deaths per 1,000 live births in 1990 to 18 deaths per 1,000 live births in 2017 [8].

A child born in sub-Saharan Africa or South Asia is ten times more likely to die in the first month of life than a child born in high-income countries [9]. In sub-Saharan Africa, central and southern Asia, around 27 and 24 newborns died for every 1,000 live births. Consequently, over 60 countries are expected to accelerate their progress towards achieving the SDGs (Sustainable Development Goals) on newborn mortality by $2030[10]$. Ensuring healthy living and promoting well-being for all age groups ending the preventable death of newborns and children under 5 years of age were a direct proposition for SDG 3[11].

Many newborn deaths could be saved with due care at birth and in the early neonatal period. Simple interventions to improve health care facilities - for example, improvement measures to help newborns to breathe during birth - have led to a reduction in newborn mortality in Tanzania [12]. According to reports from the Ethiopian Demographic and Health Survey (EDHS), the newborn death rate has not decreased significantly since 2011 and remains at around 30 newborn deaths per 1,000 live births; 37 in 2011, 29 in 2014 and 30 in 2016 and 33 in 2019[13-15].

Most neonatal deaths occur in the first week of life and $93 \%$ of NMR cases are caused by asphyxiation at birth (34\%), neonatal infections (31\%), and premature birth; Delay in seeking out-of-home treatment (delay) was associated with $81 \%$ of deaths. Health care facility delays (Delay 3 ) and transportation delays (Delay 2 ) were associated with $16 \%$ and $3 \%$ of deaths, respectively [16 17].

Therefore, the aim of this study was to assess knowledge and practical skill of essential newborn care and associated factors among nurses and midwives in Assosa zone, western Ethiopia.

\section{OBJECTIVES}

1. To assess knowledge status practice of Nurses and Midwiferys regarding to essential new born care. 
2. To identify factors associated with practice of Nurses and midwifes towards essential newborn care.

3. To identify factors associated with knowledge of Nurses and midwifes towards essential newborn care.

\section{Methodology}

\section{Study area and period}

The study was conducted in Assosa Zone governmental health facilities from April to august 2021 in western Ethiopia. Assosa zone is bordered, by Begi town Oromia region in the south, in the west by Sudan. Based on the 2007 Census conducted by the Central Statistical Agency of Ethiopia (CSA), this Zone has a total population of 310,822 , of whom 158,932 are men and 151,890 were women. 39,957 or $12.86 \%$ of population are urban inhabitants. In this Zone there are two Hospitals and 16 Health centers. A total of 72,879 households were counted in this Zone, which results in an average of 4.27 persons to a household, and 69,378 housing units.

\section{Study design}

Facility based cross-sectional study design was conducted in selected governmental health facilities of Assosa Zonea. Western Ethiopia.

\section{Population}

Source Population: The source population is all nurses and midwives who were working in governmental Health facilities of Assosa ZoneWestern Ethiopia.

\section{Study population}

The study population was those Nurses and Midwifes who were engaged in Essential newborn care service provision in Assosa Zone selected governmental health facilities during the data collection period.

\section{Inclusion and Exclusion criteria}

\section{Inclusion Criteria}

Nurses and midwives fulfilling the following criteria were included in the study:

- All midwives and nurses who were working in delivery room, neonatal intensive care unit and immediate post natal care of selected health facilities.

\section{Exclusion criteria}


- Some nurses and midwives were excluded from the study because of the following:

- Health care providers who didn't provide immediate newborn care for more than three months were excluded from the study.

- Those who were on annual leave.

Sample Size Determination

Since all nurses and midwives working in Assosa town governmental health facility were taken as sampling size, the sample size was all the number of study population which was 272 . All 272 nurses and Midwives health care providers were enrolled in the study to increase representativeness of the sample.

\section{Sampling procedures}

The maximum effort was done to ensure that all the nurses and midwives involved in Essential newborn care provision during the study period to be interviewed. The data collection was conducted during working hours also data collectors tried to reach to health facilities as early as possible to make possible arrangements for par timer workers.

\section{Procedure}

Data was collected by interviewer administered structured and pretested questionnaires. The questionnaires had four parts: part one socio-demographic characteristics, part two: personal and institutional factors, part three was knowledge of essential newborn car and part four was practice of essential new born care. The questionnaires had close ended questions and participants were given explanation to complete the necessary information by themselves. Four Bsc holders nurse and midwife were recruited for data collection. Overall, the data collection procedure was coordinated and supervised by the principal investigator.

\section{Study Variables}

\section{Dependant Variables}

Knowledge of Essential new born care

Practice of Essential new born care. Independent variables

Socio-demographic and personal institutional factors and individual related factors 


\section{Operational definition}

Good knowledge: those health care providers who correctly answer at least half of the knowledge questions are categorized as having satisfactory knowledge[18].

\section{Poor knowledge}

If the health care provider answers the knowledge questions below mean score of knowledge questions[19].

\section{Good practice}

Is when the health care providers perform more than or equal to $70 \%$ the practice procedures[20].

Poor practice If the health care providers perform less than $70 \%$ of the practice techniques[19].

\section{Data quality control}

Data collectors have been trained on the study objective and the methods of data collection. The English version of the questionnaire was created and translated into the Tigrigna version (local language). The tool was pre-tested on five percent of the sample size at Assosa Hospital Assosa town. The supervisor and principal investigator performed continuous follow-up and monitoring to ensure the completeness and consistency of the data.

\section{Data processing and analysis}

The Epi Data Manager was used to clean and enter data and then exported to SPSS version 26.0 for analysis. The knowledge questions were calculated and rated with 1 and 0 and dichotomized into good and bad knowledge. The practice of essential new born care answers on a 13-point scale: $0=$ never, $1=$ some new born care was taken into account by assigning values to Likert scale and dichotomized into 1 and 0 based on the summed value of $70 \%$ score as the cut-off point. A binary logistic regression model was used to test the statistical relationship between the outcome variable with p-value 0.2 were entered into binary logistic regressive and independent variables. The goodness of fit of the model was checked by the Hosmerlemshow test. Finally, the statistical significance was declared with a p-value $<0.05$.

\section{Research dissemination and presentation}

The research finding was presented to Assosa university department of public health. The hard copy was given to Assosa University College of health sciences, department of public health officer.

\section{Result}

Socio demographic and institutional characteristics of nurse and midwifes in Assosa zone, western, Ethiopia. 
In this study, 267 participant complete the interview which makes $98 \%$ of the response rate and the rest percent where left after many visit to get them. The largest proportion, $220(82.3 \%)$ of the respondents were between the ages of 20 and 35 years. One hundred eighty nine (69.6\%) were orthodox and 107 $(40 \%)$ were a degree holder, $107(41 \%)$ were midwifery profession $(50.3 \%)$. One hundred seven $(40 \%)$ of participants were trained about newborn care entirely. One hundred seventy two $(64.5 \%)$ of health professionals had equipment's for immediate newborn care. One hundred eight four (69\%) of the study participants had enough drugs and vaccines for caring the newborns (see Table 1). 
Table 1

Socio-demographic and institutional characteristics of nurse and midwifes in Assosa zone health facilities Benishangul gumuz, Ethiopia, 2021.

\begin{tabular}{|c|c|c|}
\hline Variable & Frequency & Percentage \\
\hline \multicolumn{3}{|l|}{ Age } \\
\hline 1. $20-35$ & 220 & 82.3 \\
\hline 2. $36-46$ & 40 & 14.2 \\
\hline 3. $>46$ & 7 & 3.5 \\
\hline \multicolumn{3}{|l|}{ Sex } \\
\hline 1. Male & 121 & 45.5 \\
\hline 2. Female & 146 & 54.5 \\
\hline \multicolumn{3}{|l|}{ Religion } \\
\hline 1. Orthodox & 189 & 69.6 \\
\hline 2. Muslim & 72 & 27 \\
\hline 3.Others & 6 & 3.5 \\
\hline \multicolumn{3}{|c|}{ Educational status } \\
\hline 1. Degree & 107 & 40 \\
\hline 2. Diploma & 160 & 60 \\
\hline \multicolumn{3}{|l|}{ Marital status } \\
\hline 1. Married & 126 & 47 \\
\hline 2. Single & 136 & 51 \\
\hline 3. Divorced & 5 & 2 \\
\hline \multicolumn{3}{|l|}{ Field of study } \\
\hline 1. Nurse & 158 & 59 \\
\hline 2. Midwifery & 109 & 41 \\
\hline \multicolumn{3}{|l|}{ Monthly salary } \\
\hline 1. 2. $2500-3114$ & 91 & 34 \\
\hline 2. $2214-4446$ & 09 & 41 \\
\hline 3. $>4446$ & 178 & 24 \\
\hline
\end{tabular}




\begin{tabular}{|lll|}
\hline Variable & Frequency & Percentage \\
\hline 1. 0 -2 years & 115 & 43 \\
\hline 2. 2-4 years & 88 & 33 \\
3. > 4 years & 56 & 21 \\
Workload & & \\
1. Yes & 227 & 85 \\
\hline 2. No & 40 & 15 \\
\hline Training on immediate newborn care & & \\
\hline 1. Yes & 105 & 39 \\
\hline 2. No & 162 & 61 \\
\hline Availability of equipments & & \\
\hline 1. Yes & 172 & 64.5 \\
\hline 2. No & 95 & 35.5 \\
\hline Availability of drugs and vaccines. & & \\
\hline 1. Yes & 184 & 69 \\
\hline 2. No & 83 & 31 \\
\hline
\end{tabular}

\section{Knowledge Of Essential Newborn Care Services}

This study reports that; the overall mean score of participants had good knowledge of newborn care was $61.7 \%$ [95 $\mathrm{Cl}(56.4,69.8)]$. One hundred seventy five $(65.5 \%)$ of participants started newborn care immediately after birth. One hundred thirty five (50.5\%) of the participants used skin to skin contact to prevent hypothermia. About 199 (74.6\%) of the respondents' used a bag and mask for ventilation. Concerning the breastfeeding, about 196 (73.4\%) of the participants reported that breastfeeding should be initiated within the first hour of birth. Eighty nine (33.2\%) of study participants agreed on the umbilical cord should tie 2-3 min of delivery/after pulsation stop. One hundred eighty five (69.2\%) used sterile Scissor to cut the umbilical cord. $(S D= \pm 3.68)$ (See Table 2). 
Table 2

Knowledge of Nurse and midwiferies on essential newborn care in Assosa zone, western Ethiopia, 2021

Variable

Frequency Percentage

Knowledge variables

When starting ENBC

1. Before birth

29

11

2. During birth

59

22

3. Immediate after birth

175

65.5

4. I don't know

4

1.5

After birth newborn kept on

1. Beside the mother

76

28.4

2. With someone else

15

3. On the mother's chest/ belly

152

24

5.6

4. On newborn bed /table

Method to prevent hypothermia

1. Immediately drying

98

36.5

2. Allowing skin to skin contact

135

50.5

3. Early bathing

23

8.8

4. Other

11

4.2

Measures if the baby not cries

1. Cover the baby and allow the skin to skin contact

57

21.4

2. Call a help and start resuscitation

182

68.3

3. Put baby on the newborn table and give mother care

22

8.3

4. Other

6

2.1

The position of the baby's head to help open the airway

1. A flexed position of the head

\begin{tabular}{|l|l|}
\hline 55 & 20.6 \\
\hline 191 & 71.5 \\
\hline 17 & 6.4 \\
\hline 4 & 1.5 \\
\hline
\end{tabular}


The mentioned measures if the baby is not breathing well after stimulation.

1. More stimulation to breath

2. Ventilation with bag and mask

3. Other

Recommended breath per minutes during ventilation

1. 30 breaths per minute

2. 40 breaths per minutes

3. 60 breaths per minute Initiation of breastfeeding after birth

1. After $6 \mathrm{~h}$ of delivery

2. Within $1-6 \mathrm{~h}$ of delivery

3. Within the first hour of delivery

4. Other

Colostrum has infection protection role

1. Yes

2. No

3.I don't know

Time to clamp or tie the umbilical cord of a crying baby

1. Clamp or tie immediately

2. Clamp or tie 1-2 min of delivery

3.Clamp or tie 2-3 min of delivery/after pulsation stop

Instrument to cut the cord

1. Clean scissor

2. New surgical blade

3. New razor blade

4. Sterile scissor

5. Other
64

23.8

199

74.6

4

1.6

$4 \quad 1.6$

55

20.7

125

47.0

87

32.3

$87 \quad 32.3$

20

7.5

44

16.5

196

73.4

7

2.6

$\begin{array}{ll}7 & 2.6\end{array}$

222

83.3

32

11.8

13

4.9

4.9

105

39.3

73

27.5

89

33.2

52

19.4

17

6.5

10

3.6

185

69.2

3

1.3 
Treatment of eye infection in newborn

1. Clean it with soap and water and cover with a bandage

23

8.7

2. Clean it with soap and water, dry it and do not cover

$28 \quad 10.5$

3. Use alcohol to clean the umbilicus

$204 \quad 76.4$

4. Other

$12 \quad 4.4$

Action to prevent bleeding in newborn

1. Breastfeed the child

$6 \quad 3.4$

2. Not necessary to give anything

$4 \quad 2.2$

3. Give vitamin $\mathrm{K}$

$166 \quad 92.7$

4. Other

$\begin{array}{ll}3 & 1.7\end{array}$

The dose of Vitamin $\mathrm{k}$ for preterm babies

1. $1 \mathrm{mg}$

$57 \quad 21.6$

2. $0.5 \mathrm{mg}$

$197 \quad 73.7$

3. Other

13

4.7

Low birth weight

1. $<3000 \mathrm{gm}$

114

2. $<2500 \mathrm{gm}$

$126 \quad 47.3$

3. $<1500 \mathrm{gm}$

$\begin{array}{ll}79 & 29.7\end{array}$

4. $<1000 \mathrm{gm}$

$51 \quad 19$

Care for low birth weight

1. Bath often

$41 \quad 15.6$

2. Breastfeeding early and frequently

$96 \quad 36.0$

3. Keep the child warm

$108 \quad 40.3$

4. Prevent infection from developing

22

8.1

Time of postnatal care appointment

1. Within the first $24 \mathrm{hr}$ of delivery

$178 \quad 67$

2. On the 3rd day of delivery

$41 \quad 15.2$

3. On the 7th day of delivery

$38 \quad 14.1$




\section{Practice Of Nurse And Midwiferies On Essential Newborn Care}

Regards to Essential newborn care practices, 179 (67\%) of our study participants washed their hand before the procedure. The mean score of good of practice essential new born care was found to be 41.5 percents with $41.5 \%$ [95\% $\mathrm{Cl}(38.3,48.5)]$. One hundred thirty-four $(74.9 \%)$ used a sterile glove, 181 (67.8\%) used an apron, and $211(79 \%)$ used a mask during the procedure of newborn care practice. One hundred eighty eight (70.4\%) of the study participants wiped eye \& face immediately after delivery. One hundred fifty (83.8\%) dried the baby immediately with a dry towel. About 223 (83.6\%) study participants performed skin-to-skin contact with the caregiver of the newborn. Two hundred thirty six (88.4\%) of the participants were counseled mother about danger sign of newborns before discharge (See Table 3) 
Table 3

Practice of Nurse and midwiferies on essential newborn care in Assosa Zone, western Ethiopia, 2021

\begin{tabular}{|c|c|c|}
\hline Variable & Frequency & Percentage \\
\hline \multicolumn{3}{|c|}{ Hand washing before procedure } \\
\hline 1. No, never & 88 & 33.1 \\
\hline 2. Yes, performed & 179 & 66.9 \\
\hline \multicolumn{3}{|l|}{ Put on sterile glove } \\
\hline 1. No, never & 78 & 29.3 \\
\hline 2. Yes, performed & 134 & 70.7 \\
\hline \multicolumn{3}{|l|}{ Wearing apron } \\
\hline 1. No, never & 86 & 32.3 \\
\hline 2. Yes, performed & 181 & 67.7 \\
\hline \multicolumn{3}{|l|}{ Wearing mask } \\
\hline 1. No, never & 56 & 21 \\
\hline 2. Yes, performed & 211 & 79 \\
\hline \multicolumn{3}{|c|}{ Wipe the eye \&face when the head is delivered } \\
\hline 1. No, never & 79 & 29.6 \\
\hline 2. Yes, performed & 188 & 70.4 \\
\hline \multicolumn{3}{|c|}{ Dry the baby immediately with dry towel } \\
\hline 1. No, never & 49 & 18.5 \\
\hline 2. Yes, performed & 218 & 81.5 \\
\hline \multicolumn{3}{|c|}{ Check \& sucks the airway after delivery } \\
\hline 1. No, never & 52 & 19.6 \\
\hline 2. Yes, performed & 215 & 80.4 \\
\hline \multicolumn{3}{|l|}{ Take APGAR score } \\
\hline 1. No, never & 76 & 28.4 \\
\hline 2. Yes, performed & 191 & 71.6 \\
\hline
\end{tabular}




\begin{tabular}{|lll|}
\hline Variable & Frequency & Percentage \\
\hline 1. No, never & 58 & 21.7 \\
2. Yes, performed & 209 & 78.3 \\
\hline Give eye ointment & & \\
\hline 1. No, never & 53 & 19.8 \\
\hline 2. Yes, performed & 214 & 80.2 \\
\hline Counsel mother about newborn danger sign before discharge & & \\
\hline 1. No, never & 31 & 11.6 \\
\hline 2. Yes, performed & 236 & 88.4 \\
\hline Weigh \& record the baby's weight & & \\
\hline 1. No, never & 49 & 18.5 \\
\hline 2. Yes, performed & 218 & 81.5 \\
\hline Skin to skin contact & & \\
\hline 1. No, never & 223 & 83.6 \\
\hline 2. Yes, performed & 44 & 16.4 \\
\hline
\end{tabular}

\section{Factors Associated With Knowledge And Practice Of Enc}

In order to identify factors associated with knowledge of ENC, logistic regression forward method was used with $95 \% \mathrm{Cl}$ and $\mathrm{p}$-value $<5 \%$, variables those have association in bivariate logistic regression were entered to multivariate logistic regression and final independent predictors of ENC were identified.

Availability of newborn care equipments being trained on ENC and educational status were found to have significant association with participants' of knowledge of essential newborn care.

Factors significantly associated with essential new born care knowledge were; training on essential newborn care [AOR $(95 \% \mathrm{Cl}) ; 3.65(3.61,4.07)]$,educational level [AOR $(95 \% \mathrm{Cl}) ; 2,27(2.18,2.68)]$ and Availability of knowledge of ENC [AOR $(95 \% \mathrm{Cl}) ; 2.25(2.08,3.46)]$ as well as practice of essential new born care was significantly associated with two factors : availability of drugs [AOR $(95 \% \mathrm{Cl}) ; 2.04(1.85,2.43)$ ] and being trained on essential new born care [AOR $(95 \% \mathrm{Cl}) ; 4.83(4.36,5.07)]$ (See Table 4). 
Table 4

Factors associated with knowledge of Essential new born care

\begin{tabular}{|c|c|c|c|c|c|c|}
\hline \multirow[t]{2}{*}{ Variables } & & \multicolumn{2}{|c|}{$\begin{array}{l}\text { Knowledge of } \\
\text { ENC }\end{array}$} & \multirow[t]{2}{*}{ COR (95\% Cl) } & \multirow[t]{2}{*}{ AOR $(95 \% \mathrm{Cl})$} & \multirow[t]{2}{*}{ P-Val } \\
\hline & & Good & poor & & & \\
\hline \multirow[t]{2}{*}{ Trained on ENC } & Yes & 68 & 37 & $3.29(2.832,3.45)$ & $3.65(3.61,4.07)$ & 0.023 \\
\hline & No & 58 & 104 & 1 & 1 & \\
\hline \multirow[t]{2}{*}{ Educational status } & Degree & 65 & 42 & $2.04(1.72,2.45)$ & $2.27(2.18,2.68)$ & 0.034 \\
\hline & Diploma & 69 & 91 & 1 & 1 & \\
\hline \multirow{2}{*}{$\begin{array}{l}\text { Availability of ENC } \\
\text { Materials }\end{array}$} & Yes & 113 & 60 & $1.52(1.22,2.12)$ & $2.25(2.08,3.46)$ & 0.002 \\
\hline & No & 52 & 42 & 1 & 1 & \\
\hline \multirow[t]{2}{*}{ Variables } & & \multicolumn{2}{|c|}{$\begin{array}{l}\text { Practice of } \\
\text { ENC. }\end{array}$} & COR (95\% Cl) & AOR (95\% Cl) & P-Val \\
\hline & & Good & poor & & & \\
\hline \multirow[t]{2}{*}{ Work experience } & $<5$ years & 131 & 80 & $0.36(0.31,0.44)$ & $0.45(0.32,0.52)$ & 0.015 \\
\hline & $>5$ years & 46 & 10 & 1 & 1 & \\
\hline \multirow[t]{2}{*}{ Work load } & Yes & 116 & 111 & $0.56(0.44,0.86)$ & $0.87(0.64,1.67)$ & 0.056 \\
\hline & No & 21 & 19 & 1 & 1 & \\
\hline \multirow[t]{2}{*}{ Trained on ENC } & Yes & 71 & 34 & $3.46(3.12,3.52)$ & $4.83(4.36,5.07)$ & 0.001 \\
\hline & No & 61 & 101 & 1 & 1 & \\
\hline
\end{tabular}

\section{Discussion}

The first hours after birth are the critical phase in an infant's life for further growth and development, which is largely, depends on the quality essential new born of care given. In this study the overall knowledge score of essential new born was $61.7 \%$ at $95 \% \mathrm{Cl}(56.4,69.8)]$ which is in line with the Study conducted in Wolaita zone southern Ethiopia in which knowledge score of ENC was $57.9 \%$ [21] and in Bahirdar 56\%[22]. But this finding was higher than the study conducted in Bamako in Mali 54\% [23] and in Masindi Uganda was 46.5\%[24]. However our finding is less than the study conducted in India was $76 \%$ [25] and in Tigray was 74.6\% [26].The discrepancy could be due to the difference in in-service training, difference of educational level of study participants and study setting.

Overall, it was found that the average good practice score was the basic neonatal care $41.5 \%$ at $95 \% \mathrm{Cl}$ $(38.3,48.5)$. This finding is relatively lower than what it should be as Ethiopian expectation strategic plan. Our finding is nearly similar to a study conducted in Gurage zone Southwest of Ethiopia (41\%)[27] and 
Nekemte city 44.1\%[28], western Ethiopia. However less than the study done in Afar North East Ethiopia in which good practice of ENC is 62.7\% [29] and in Tigray Northwestern Ethiopia 59.8\% [30]. These differences could largely due to the different educational levels of participants and access to essential neonatal care training for healthcare providers.

In this study' training on essential new born care brought significant change of essential newborn care knowledges; in which those trained nurse and midwives were three times more likely knowledgeable than their counterparts. This finding is consistent with the study conducted in West Guji, Ethiopia in on those service trained had more knowledge of essential newborn care than untrained health care providers[31] and the study conducted in Afar North East Ethiopia[32].

Another factor significantly associated in multiple logistic regression was educational qualification. Those degree holders; health care providers in our study were 2.27 times more likely have knowledgeable of Essential newborn care than diploma holders of health care providers. This find is supported by the study conducted in Jimma Zone, Ethiopia in which diploma holders of health care providers were $70 \%$ less likely had knowledge of Essential new born care [33].

The availability of drugs for ENC was also significant factors for knowledge of Essential new born care in which the health care providers those who were working in faculty with availability drugs for ENC were 2.25 time more likely have knowledge of essential newborn care than those responded no availability of drugs for ENC in the facility where they were working. This result is supported by the study conducted in Northern Ethiopia in Tigray region [34] and the study done in Nigeria [35].

In regards to the factors associated with practice of ENC among Nurse and Midwives; work experience was significantly associated with practice of essential newborn care in which those health care providers' works less than five years were $64 \%$ less likely have good practice of essential newborn care services. This outcome is supported by the study done in west Guji, Oromia region Ethiopia in which working more than three years was associate with good practice of essential newborn care[31] similarly supported by the study done in Bossaso, Somalia[36].

\section{Limitations}

Limitations in the present study include the use of a consecutive sample, which precludes external generalization of the study results. Results were based on self-reports and may not be as objective as actual observation of the practices. Finally, the study did not examine the influence of culture, in which case a qualitative approach would have been desirable. This could be priority area of future research.

\section{Conclusion}

The knowledge of essential newborn care was somewhat average among Nurse and Midwifes; however, the practice of essential newborn care was very low compared to other studies in Ethiopia. On-the-job training, Availability ENC materials and educational qualification were the factors associated with a good 
knowledge of ENC; while Working experience and the availability of on-the-job training were the factors associated with a good practice of Essential newborn care. Therefore, concerned bodies should consider the provision of refreshment on-the job training, upgrading the qualification of health professionals, and providing incentives and motivators to improve interest in working in the delivery room.

\section{Recommendations:}

Based on the study results; forwarded the following recommendations to the respective institutions and bodies:-

- Promote regular training for healthcare professionals on immediate neonatal care for government and nongovernmental health organizations

- Incentivize health care facility managers to those with good knowledge and experience of postpartum care.

- The curriculum for the student should include all of the steps outlined for the Immediate Baby for the College of Medicine and Health Science.

- Further in-depth study of knowledge and practice of health professionals is required.

\section{Abbreviations}

OR: odds ratio; Cl: confidence interval, SNNPR: Southern Nations Nationalities and People Region; WHO: World Health Organization, ENC:-Essential new born care.

\section{Declarations}

\section{Acknowledgement}

My deepest gratitude goes to Assosa University College of health science, for giving me opportunity to do this research. Next, I want to thank my families for their genuine support. Finally, I want to thank all directly and indirectly those who support me from the beginning up to the end of this study. It is because of all this study becomes evident.

\section{Authors' contributions}

$\underline{\mathrm{HD}}$ conceived the research idea and prepared the proposal, analyzed data and sent the manuscript.

$\underline{\text { B }}$ and $\underline{\mathrm{BK}}$ approved the proposal with some revisions, participated in data analysis, and reviewed the manuscript.

MDparticipate in designing and analyzing the data

All authors approved the final draft of the manuscript. 
All the authors read and approved the final manuscript.

Funding information

No funding.

Availability of data and materials

The datasets used and/or analyzed during the current study available from the corresponding author on reasonable request.

Ethics approval

Ethical clearance was obtained from Assosa University Institutional Review Board. Permission letter was obtained from the Benishangul gumuz regional health bureau.

Name of Ethical review board: Assosa University institutional research Ethical review Board.

Consent to participate

Verbal consent is obtained from the participant which is approved by the Assosa University Ethical review board.

\section{Consent for publication}

Not applicable for this section.

\section{Competing interests}

The authors declare that they have no competing interests.

\section{References}

1. Silvestre A. Early essential newborn care: Clinical practice pocket guide. World Health Organization. Regional Office for the Western Pacific 2014

2. WHO. Newborns: improving survival and well-being, 2020.

3. Organization WH. WHO recommendations on newborn health: guidelines approved by the WHO Guidelines Review Committee: World Health Organization, 2017.

4. Organization WH. Newborn care until the first week of life: clinical practice pocket guide. 2009

5. Gibson A, Noguchi L, Kinney MV, et al. Galvanizing collective action to accelerate reductions in maternal and newborn mortality and prevention of stillbirths. Global Health: Science and Practice 2021;9(2):268

6. Roué J-M, Kuhn P, Maestro ML, et al. Eight principles for patient-centred and family-centred care for newborns in the neonatal intensive care unit. Archives of Disease in Childhood-Fetal and Neonatal 


\section{Edition 2017;102(4):F364-F68}

7. Organization WH. WHO recommendations on child health: guidelines approved by the WHO Guidelines Review Committee: World Health Organization, 2017.

8. Hug L, Alexander M, You D, Alkema L, for Child UNI-aG. National, regional, and global levels and trends in neonatal mortality between 1990 and 2017, with scenario-based projections to 2030: a systematic analysis. The Lancet Global Health 2019;7(6):e710-e20

9. Neefjes P. Current Developments in Global Child Health Care: unicef Data and Experiences. Children's Rights in Health Care: Brill Nijhoff, 2018:32-47.

10. UNICEF, Unicef. Strategy for health 2016-2030. 2016

11. Organization WH. Health in 2015: from MDGs, millennium development goals to SDGs, sustainable development goals. 2015

12. Makene CL, Plotkin $\mathrm{M}$, Currie $\mathrm{S}$, et al. Improvements in newborn care and newborn resuscitation following a quality improvement program at scale: results from a before and after study in Tanzania. BMC Pregnancy Childbirth 2014;14(1):1-11

13. CSa I. Central statistical agency (CSA)[Ethiopia] and ICF 2011. Ethiopia demographic and health survey, Addis Ababa, Ethiopia and Calverton, Maryland, USA, 2011.

14. Csao. Ethiopia Demographic and Health Survey 2016. Addis Ababa, Ethiopia, and Rockville, Maryland, USA: CSA and ICF, 2016.

15. Csa E. Ethiopia Demographic and Health Survey 2019. Addis Ababa, Ethiopia, and Rockville, Maryland, USA: CSA and ICF. 2019

16. Waiswa P, Kallander K, Peterson S, Tomson G, Pariyo GW. Using the three delays model to understand why newborn babies die in eastern Uganda. Trop. Med. Int. Health 2010;15(8):964-72

17. Bogale TN, Worku AG, Bikis GA, Kebede ZT. Why gone too soon? Examining social determinants of neonatal deaths in northwest Ethiopia using the three delay model approach. BMC Pediatr. 2017;17(1):1-8

18. Yosef T, Getachew D, Weldekidan F. Health professionals' knowledge and practice of essential newborn care at public health facilities in Bench-Sheko Zone, southwest Ethiopia. Heliyon 2021;7(11):e08369

19. Abdu H, Gebrselassie M, Abdu M, Mare KU, Tadesse W, Liben ML. Knowledge and practice of immediate newborn care among midwives and nurses in public health facilities of Afar regional state, Northeast Ethiopia. BMC Pregnancy Childbirth 2019;19(1):1-10

20. Ashenef G, Eshete A, Zegeye B, Tarekegn TT, Taderegew MM. Essential newborn care practice and associated factors among health care providers in Northeast Ethiopia: a cross-sectional study. Archives of Public Health 2021;79(1):1-8

21. Arba A, Zana Z. Knowledge of Essential Newborn Care and Associated Factors among Nurses and Midwives: A Cross-Sectional Study at Public Health Facilities in Wolaita Zone, Southern Ethiopia, 
2019. Int. J. Pediatr. 2020;2020:3647309-09 doi: 10.1155/2020/3647309[published Online First: Epub Date]|.

22. Yemaneh $Y$, Dagnachew E. Knowledge and practice of immediate new born care (inc.) among health professionals in governmental health facilities of Bahir Dar City, North Ethiopia 2016. Qual. Prim. Care 2017;25(6):360-67

23. Traoré FD, Sylla $M$, Diall $H$, et al. Knowledge of health professionals on essential newborn care in Bamako, Mali. Open Journal of Pediatrics 2018;8(04):311

24. Ayiasi RM, Criel B, Orach CG, Nabiwemba E, Kolsteren P. Primary healthcare worker knowledge related to prenatal and immediate newborn care: a cross sectional study in Masindi, Uganda. BMC Health Serv. Res. 2014;14(1):1-11

25. Malhotra S, Zodpey SP, Vidyasagaran AL, et al. Assessment of essential newborn care services in secondary-level facilities from two districts of India. Journal of health, population, and nutrition 2014;32(1):130

26. Berhe AK, Tinsae F, Gebreegziabher G. Knowledge and practice of immediate newborn care among health care providers in eastern zone public health facilities, Tigray, Ethiopia, 2016. BMC Pediatr. 2017;17(1):1-9

27. Abebe H, Adane D, Shitu S. Essential newborn care practice and its associated factors in Southwest Ethiopia. Archives of Public Health 2021;79(1):1-9

28. Efa BW, Berhanie E, Desta KW, et al. Essential new-born care practices and associated factors among post natal mothers in Nekemte City, Western Ethiopia. PLoS One 2020;15(4):e0231354

29. Ayenew A, Abebe M, Ewnetu M. Essential Newborn Care and Associated Factors Among Obstetrical Care Providers in Awi Zone Health Facilities, Northwest Ethiopia: An Institutional-Based CrossSectional Study. Pediatric Health Med Ther 2020;11:449-58 doi: 10.2147/PHMT.S276698[published Online First: Epub Date]l.

30. Tasew H, Teshale T, Bahrey D, Mariye T, Teklay G. Immediate newborn care of knowledge, practice and associated factors among health care providers in northwestern zonal health facilities Tigray, Ethiopia, 2018. BMC Res. Notes 2019;12(1):1-8

31. Rajan DR, Jaldo D, Gemechu T, Kasimayan P, Kasirajan AK. Quality of Essential Newborn Care and its Associated Factors in Public Health Facilities of West Gujji, Oromia, Ethiopia: A Cross Sectional Study. Annals of the Romanian Society for Cell Biology 2021:7616-29-16-29

32. Abdu H, Gebrselassie M, Abdu M, Mare KU, Tadesse W, Liben ML. Knowledge and practice of immediate newborn care among midwives and nurses in public health facilities of Afar regional state, Northeast Ethiopia. BMC Pregnancy Childbirth 2019;19(1):422 doi: 10.1186/s12884-019-25813[published Online First: Epub Date]|.

33. Negussie B, Hailu F, Megenta A. Knowledge and practice of essential newborn care and associated factors among nurses and midwives working at health centers in Jimma Zone, Ethiopia, 2016. J. Nurs. Care 2018;7(446):2167-8 
34. Tasew H, Teshale T, Bahrey D, Mariye T, Teklay G. Immediate newborn care of knowledge, practice and associated factors among health care providers in Northwestern Zonal health facilities Tigray, Ethiopia, 2018. BMC Res. Notes 2019;12(1):427 doi: 10.1186/s13104-019-4465-z[published Online First: Epub Date]|.

35. Esan DT, Adedeji OA, Bello CB, Omolafe MC. Knowledge and practices of immediate newborn care among midwives in selected health care facilities in Ekiti State, Nigeria. Pan Afr. Med. J. 2020;37:263 doi: 10.11604/pamj.2020.37.263.24628[published Online First: Epub Date]|.

36. Amsalu R, Morris CN, Chukwumalu K, et al. Essential newborn care practice at four primary health facilities in conflict affected areas of Bossaso, Somalia: a cross-sectional study. Conflict and health 2019;13(1):1-13

\section{Supplementary Files}

This is a list of supplementary files associated with this preprint. Click to download.

- NEWBORNTOOL.docx 